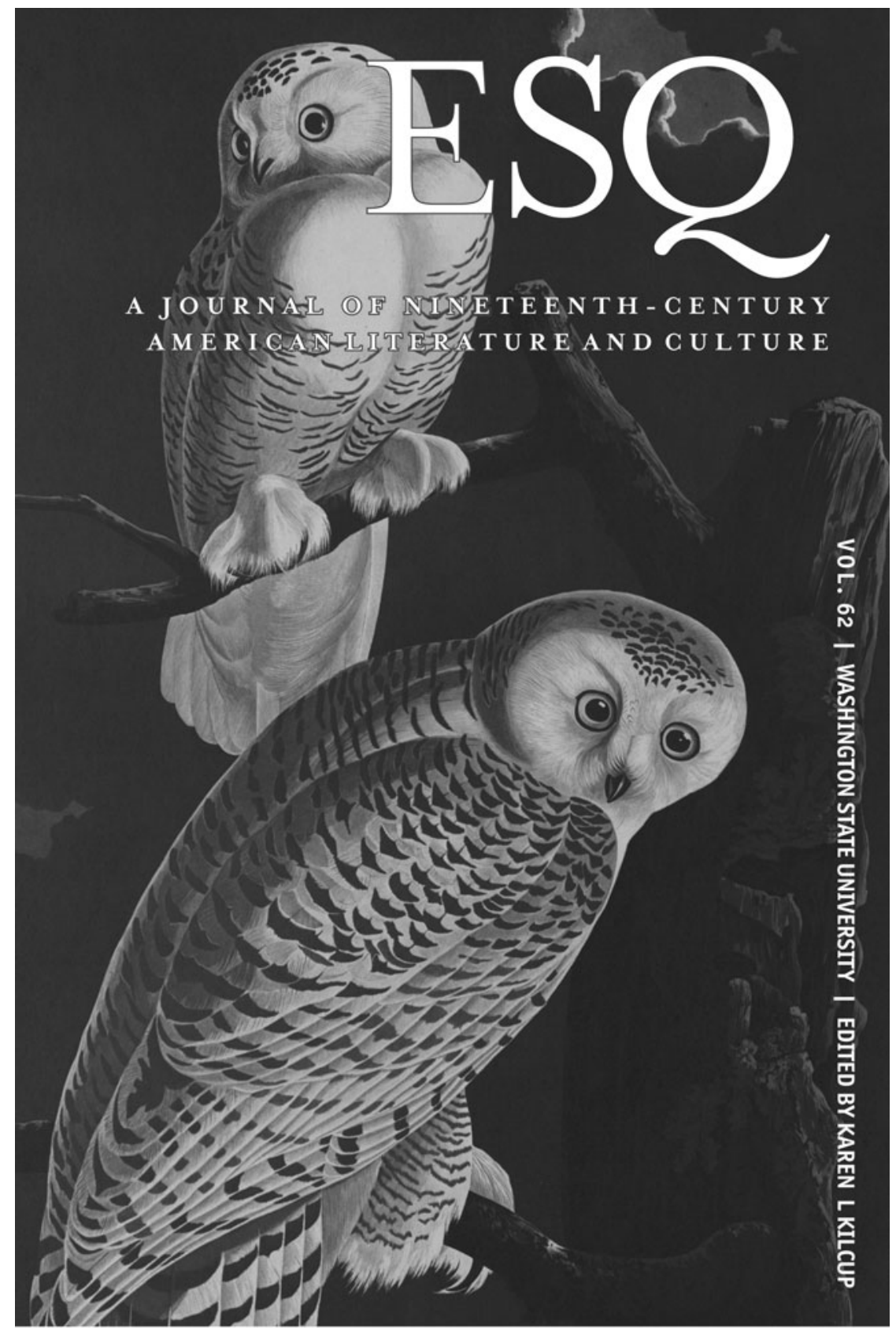

Find us on Facebook and Twitter (@esqjournal) or visit our website at english.wsu.edu/esq-home Please send submissions and inquiries to esq@wsu.edu 


\section{HOLDING ON}

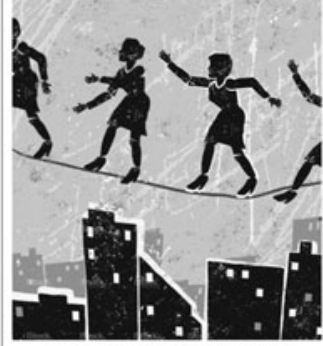

$\$ 30.00$

PAPERBACK

AFRICAN AMERICAN WOMEN

SURVIVING HIV/AIDS I Alpron ODaniel

Moments of Impact

Injury, Racialized Memory, and Reconciliation in

College Football

Jaime Schultz

$\$ 40.00 \cdot$ HARDCOVER

Intersectionality

Origins, Contestations, Horizons

Anna Carastathis

$\$ 55.00 \cdot$ HARDCOVER

Available November 2016

Romance with Voluptuousness

Caribbean Women and Thick Bodies in the

United States

Kamille Gentles-Peart

$\$ 45.00 \cdot$ HARDCOVER

Available October 2016

Rebuilding Shattered Worlds

Creating Community by Voicing the Past

Andrea L. Smith and Anna Eisenstein

$\$ 30.00 \cdot$ PAPERBACK

Available October 2016

Dressing for the Culture Wars

Style and the Politics of Self-Presentation in the 1960 s and 1970 s

Betty Luther Hillman

$\$ 40.00 \cdot$ HARDCOVER

Capitalist Family Values

Gender, Work, and Corporate Culture at Boeing

Polly Reed Myers

$\$ 50.00 \cdot$ HARDCOVER

Scarlet Experiment

Birds and Humans in America

Jeff Karnicky

$\$ 45.00 \cdot$ HARDCOVER

Available November 2016

NEBRASKAPRESS.UNL.EDU • UNPBLOG.COM

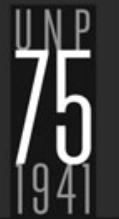




\section{Instructions for contributors}

\section{Editorial policy}

Journal of American Studies publishes works by scholars from all over the world on American literatures, history, politics, foreign relations, philosophy, art history, visual culture, economics, film, popular culture, geography, material culture and related subjects. We also welcome research topics covering fields related to American Studies and which include (in alphabetical order): African American Studies; African Diasporic Studies; America in the World Studies; Asian American Studies; Chicana/o and Latina/o Studies; Chinese American Studies; Cultural Studies; Globalisation Studies; Indigenous Studies; Hemispheric Studies; Slavery Studies; Transatlantic Studies; Transnational Studies. A Notes and Comments section provides a forum for shorter pieces and responses from readers to points made in articles, reviews, states of the field/thought pieces/review essays/ roundtable contributions. We are also keen to consider contributions that go beyond the normal confines of an academic article - whether these be Research Notes, States of the Field pieces, Thought Pieces, Forums and Roundtable Discussions, Exhibition Commentaries, Research Notes. Proposals on this front should be emailed directly to the editors.

Journal of American Studies welcomes proposals for special issues or special collections of essays within an issue. Proposing editors should initially submit a synopsis of a minimum of 1500 words detailing the academic significance of the collection, and 200 words abstracts of each of the essays as well as a one line contributor biography. These will be considered by the JAS Editorial Team and the journal's Editorial Board and then sent to readers for feedback. If the proposal passes the initial stage, JAS will then invite full essays, to be read and reviewed using our standard process for submissions.

For more information, please contact the Co-Editors: Professor Celeste-Marie Bernier and Dr. Bevan Sewell (full contact information provided below).

\section{Book reviews}

Editorial correspondence relating to book reviews should be sent to the following address: Dr Sinéad Moynihan, Department of English, University of Exeter, The Queen's Building, The Queen's Drive, Exeter EX4 4QJ, UK, Email: jasreviews@exeter.ac.uk

\section{Submissions}

Papers should be submitted online via the following website at: http://mc.manuscriptcentral.com/jamstuds. Authors who do not yet have an account on the online submission site will need to register before submitting a manuscript. If you are unsure about your login details or whether you have an account or not, please use the password help field on the login page. Do not create a new account if you are unsure.

If you experience any difficulties submitting your manuscript, please contact ScholarOne support at http:// mchelp.manuscriptcentral.com/gethelpnow/question.htm
Any editorial correspondence should be addressed to the Co-Editors: Professor Celeste-Marie Bernier and Dr. Bevan Sewell on the following email address: jas@baas.ac.uk

Submission of an article is taken to imply that it is an original work of scholarship and has therefore not previously been published, and has not been submitted for publication elsewhere. Authors of articles published in the journal assign copyright to Cambridge University Press and British Association of American Studies (with certain rights reserved) and will receive a copyright assignment form for signature on acceptance of your paper.

Contributors are responsible for obtaining permission to reproduce any material in which they do not own copyright, to be used in both print and electronic media and as regards images rights and high resolution files, and for ensuring that the appropriate acknowledgements are included in their manuscript.

\section{Manuscript preparation}

Articles should not exceed 8,000 words (excluding footnotes) OR 12,000 words (including footnotes).

Manuscripts should be submitted via the online submission system at http://mc.manuscriptcentral.com/jamstuds. Authors should remove their name from the manuscript and should ensure that their manuscript is fully anonymised. Authors should make sure that any tracked changes on the file have been removed.

File names should be of the type AMSauthorsurname. doc or .rtf for ease of identification. Diagrams, maps, and illustrations should be made into an eps file or a tiffile and the file name should be AMSauthorsurname1.eps or .tif (where the number is the figure number) - please refer to http://assets.cambridge.org/AMS/AMS/_ifc.pdf for further information regarding technical specifications. If you request colour figures in the printed version, you will be contacted by CCC-Rightslink who are acting on our behalf to collect Author Charges. Please follow their instructions in order to avoid any delay in the publication of your article.

Contributors should keep one copy of the typescript for correcting proofs.

Open Access Policies: Please visit http://journals.cambridge. org/OpenAccess for information on our open access policies, compliance with major finding bodies, and guidelines on depositing your manuscript in an institutional repository.

\section{Text preparation}

Authors should refer to the detailed instructions provided here http://assets.cambridge.org/AMS/AMS/_ifc.pdf before submitting their work.

This journal issue has been printed on FSC-certified paper and cover board. FSC is an independent, non-governmental, not-for-profit organization established to promote the responsible management of the world's forests. Please see www.fsc. org for information. 


\section{JOURNAL OF AMERICAN STUDIES}

\section{VOLUME 50 ISSUE 2 MAY 2016}

v Editors' Note

279 BAAS Keynote Speech A Passion for Democracy: Proximity to Power and the Sovereign Immunity Test

Dana D. Nelson

\section{IMMIGRATION FORUM}

305 The Undocumented Everyday: Migrant Rights and Visual Strategies in the work of Alex Rivera Rebecca M. Schreiber

329 Madness, Entropy, Paradox: The Legacy of Political Violence in Loida Maritza Pérez's Geographies of Home

Jennifer Krause

347 "What Must Be the Answer of the United States to Such a Proposition?" Anarchist Exclusion and National Security in the United States, 1887-1903

\section{Alexander Noonan}

377 The International Consequences of American National Origins Quotas: The Australian Case David C. Atkinson

397 The "Dulles Doctrine on Love": Immigration, Gender, and Romance in American Diplomacy, 1956-1957 Anne M. Blaschke

419 Americanization Now and Then: The "Nation of Immigrants" in the Early Twentieth and Twenty-First Centuries

Maria Lauret

\section{COMMENTARIES}

449 Immigration Forum Comment: Cultural Responses to Immigration Stephanie Lewthwaite

459 Immigration Forum Comment: Foreign Relations and Migration

Meredith Oyen

\section{REVIEW ESSAY}

465 Does the Movement Need a King?

Peter J. Ling

471 REVIEWS

ELECTRONIC CONTENT

REVIEW ESSAY

EXCLUSIVE ONLINE REVIEWS www.journals.cambridge.org/ams

\section{Cambridge Journals Online}

